\title{
Influence of continuous plastic fibers reinforcement arrangement in concrete strengthened
}

\author{
F.J. Baldenebro-Lopez ${ }^{1,2}$, J.H. Castorena-Gonzalez ${ }^{2}$, J.I. Velazquez-Dimas ${ }^{3}$, \\ J.E. Ledezma-Sillas ${ }^{1}$, C.D. Gómez-Esparza ${ }^{1}$, R. Martinez-Sanchez ${ }^{1}$, \\ J.M. Herrera-Ramirez ${ }^{1, *}$ \\ ${ }^{I}$ Centro de Investigación en Materiales Avanzados (CIMAV), Laboratorio Nacional de Nanotecnología, Miguel \\ de Cervantes No. 120, 31109 Chihuahua, Chih., México. \\ ${ }^{2}$ Facultad de Ingeniería Mochis, Universidad Autónoma de Sinaloa. Fuente de Poseidón y Prol. Angel Flores \\ S/N, 81223 Los Mochis, Sinaloa, México. \\ ${ }^{3}$ Facultad de Ingeniería, Universidad Autónoma de Sinaloa, Calzada de las Américas y B. Universitarios S/N, \\ 80040 Culiacán, Sinaloa, México.
}

\begin{abstract}
Many studies have been done using waste short plastic fibers to reinforce concrete. The objective of this investigation is the development of a novel arrangement of reinforcement with continuous recycled PET fibers, to enhance the mechanical properties of concrete beams. The novel arrangement consists of continuous PET fibers of the same length as concrete beams, placed in the mold, fixed and prestressed prior to casting the concrete. Due to the fact that in previous investigations on concrete reinforced with PET fibers, these fibers have been used in a short, dispersed way; it is of interest to compare the effect of the novel arrangement of continuous fiber reinforcement with the typical short, discontinuous fiber reinforcement. Thus, in this paper concrete beams were reinforced using both fiber arrangements. The mechanical behavior of reinforced concrete samples were evaluated and compared by bending tests. The results showed a better performance of the continuous PET fiber reinforcement than that of the short, discontinuous one; the continuous PET samples presented a great increase in the concrete properties in $150 \%$ the maximum load in bending. Before testing the concrete composites, recycled PET fibers were mechanically and structurally characterized by FTIR, DSC and tensile tests.
\end{abstract}

Keywords: - Deformation, Fiber-reinforced concrete, Mechanical properties, Recycled PET fibers.

\section{INTRODUCTION}

Concrete is the most widely used construction material in the world due to its high compressive strength, long service life, and low cost. However, concrete has inherent disadvantages of low tensile strength and crack resistance. Numerous studies on fiber-reinforced concrete (FRC) have been performed in order to improve such weaknesses of the material. FRC is a composite material resulting from the addition of reinforcing fibers to the brittle matrix of ordinary concrete. The idea of using fibers as a concrete reinforcement comes from the need to find an improvement to the disadvantages previously mentioned; this is achieved by the "sewing effect" that the fibers have on the cracks [2].

Over the last decades the growing problem of recycling waste plastic materials has generated the need for these materials to be widely investigated. Therefore, it is necessary to find alternatives about recycling and reusing the waste plastics materials. Many investigations have been done about structural materials using plastic elements as reinforcement [4-9]. Several researches have been oriented in using recycled products in the concrete mix [3]. Waste plastics materials have been used as components in cement pastes, mortar and concrete (e.g. reinforcing fibers, fines aggregates, coarse aggregate, lightweight aggregate, and resins). It has been reported that concrete reinforced with short plastic fibers drastically improves the performance of concrete and eliminates its disadvantages, such as low tensile strength, low ductility, and low energy absorption capacity [1]. This new composite materials must be subjected to mechanical tests before their practical application in the construction industry.

The main fibers used as concrete reinforcing material are steel, glass and polymeric fibers. Some of these fibers are used in structures such as: columns [10], beams [11], and walls [12]. The polymeric fibers most frequently used as concrete reinforcements are nylon, aramid, polypropylene, polyethylene and polyester.

Bottles of polyethylene terephthalate (PET) have been replacing glass bottles as storage containers because of their easy handling, storage and lightweight. As time passes, the PET bottle production and disposal has increased exponentially. Yesilata et al. [13] reported that the addition of a mixture of crushed PET bottles and tires in the concrete improves the thermal performance. Ochi et al. [14] described a method that can be used to produce reinforcing PET fibers from waste PET bottles; the fibers were mixed with concrete in several ratios 
obtaining an increase in the flexural strength and toughness. Kim et al. [1] compared the performance capacity of a recycled PET fiber-reinforced concrete (RPETFRC) with the one of a polypropylene fiber-reinforced concrete, finding a decrease in compressive strength and elastic modulus, but an increase in ductility and ultimate strength as the fiber fraction increased. Dora [2] reported that the mechanical properties of concrete can be improved by adding low concentrations of waste PET fibers, in both lamellar and "O" forms. Fraternali et al. [15] performed a study of thermal conductivity, compressive strength, first crack strength and ductility indices of RPETFRC; noticeable improvements compared to unreinforced concrete in thermal resistance, mechanical strength and ductility were found. Pereira de Oliveira et al. [16] investigated the utilization of recycled PET bottle fiber as reinforcing fibers on cement-lime mortar samples; it was concluded that the incorporation of PET fibers significantly improves the flexural strength and toughness. After a precise literature review, it could be seen that reports of recycle PET fibers used as reinforcement in concrete are only in the state of short dispersed fibers, having a similar effect to aggregates. Moreover, there are not published papers about continuous fiberreinforced concrete investigations.

The present research determined the mechanical behavior of a concrete reinforced with a novel arrangement of continuous PET fibers, which act as beams in the concrete. PET fibers were extracted from waste PET beverage bottles, by a mechanical manufacturing process, in order to obtain continuous fibers as long as the concrete beam samples. The continuous fibers were located in the concrete beam samples areas where tensile stresses take place when the concrete is subjected to flexion.

It is well known that continuous elements reinforced concrete (CERC), such as reinforced concrete with steel bars, presents best behavior that discontinuous and scattered elements reinforced concrete (DSERC). The idealized behavior of ordinary concrete (OC), CERC and DSERC is shown in figure 1. The FRC, in the hardened state, shows the appearance of an OC; however, it presents an improvement in the mechanical behavior, such as a ductility increment and shrinkage cracks reduction. In this paper continuous fiber-reinforced concretes (CFRC) with the novel arrangement and short fiber-reinforced concretes (SFRC) were studied and compared with OC and other reported researches.

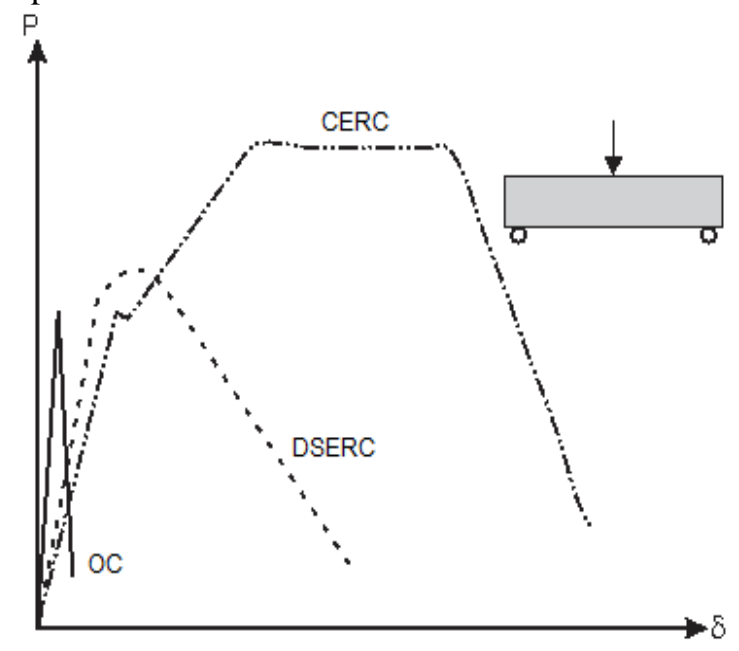

Figure 1. Load-deflection plot of the ordinary concrete and reinforced concrete beams.

\section{II.1. CONCRETE}

\section{MATERIALS AND METHODS}

The concrete mixtures were prepared using a commercial composite Portland cement (CPC-30R), river coarse aggregate (gravel) with a maximum size of $13 \mathrm{~mm}$ and river sand as fine aggregate with a fineness modulus of 3.71. The manufacture of concrete was strictly controlled to avoid deviations in the results; the amount of each ingredient is specified in table 1 . Different volumes of fibers $(0.00 \%, 0.25 \%, 0.50 \%$ and $1.00 \%)$ were used in the production of RPETFRC specimens for mechanical testing. Samples containing continuous fibers and also scattered fibers were prepared. All specimens, after being removed from the mold, were stored for 4 weeks in a humid chamber at $20^{\circ} \mathrm{C}$ and $96 \%$ RH.

Table 1. Constituents of the concrete mixture per cubic meter.

\begin{tabular}{cc}
\hline Material & Dosage $(\mathrm{kg})$ \\
\hline Cement & 21.72 \\
Water & 20.90 \\
Fine aggregate & 21.43 \\
Coarse aggregate & 20.72 \\
\hline
\end{tabular}




\section{II.2. RECYCLED PET FIBERS}

The reinforcing material for this research was obtained from different waste bottles (refreshing drinks, water, tea and juices). Bottles were collected from house hold waste and were only treated by water-based washing.

The recycled PET fibers, shown in figure 2, were obtained from PET bottles on a spiral shape through a mechanical cutting around the bottle walls. The device allowed the uniformity in width on the fibers dimensions. The fibers dimensions were approximately $4 \mathrm{~mm}$ in width, $0.34 \mathrm{~mm}$ in thickness and lengths of 40 $\mathrm{mm}$ and $600 \mathrm{~mm}$ for short and continuous fibers, respectively. The different recycled PET fibers were identified as $\mathrm{A}, \mathrm{B}, \mathrm{C}, \mathrm{D}, \mathrm{E}$ and $\mathrm{F}$ samples.

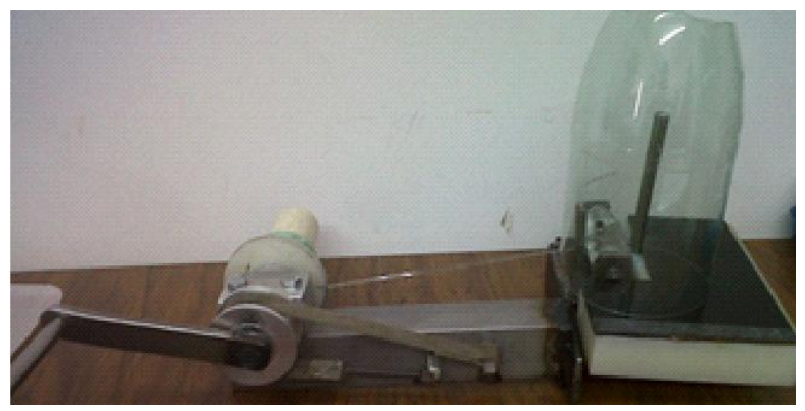

Figure 2. Device used to obtain the PET fibers.

\section{II.3. PREPARATION METHOD OF CONCRETES}

The concrete mixing was completed in four stages, using a mechanical mixer operated in a range of 28-32 RPM: Stage 1: The mixer container was moistened by adding water and it was set to rotate for 20 seconds; the water excess was drained from the mixer container.

Stage 2: $10 \%$ of water and $10 \%$ of gravel were added with the mixer working.

Stage 3: The whole amount of cement was added after 10 seconds and it was followed by the remaining of dry aggregates. The mixing time was approximately 1.5 minutes.

Stage 4: The remaining water was incorporated and the mixing continued for 4.5 minutes.

In the case of SFRC samples, a hand-made mixture of cement and fibers was previously elaborated and added as indicated in stage 3. As it can be observed in figure 3a, concretes mixed with short PET fibers (SFRC) exhibited good fiber dispersion. Regarding CFRC samples, the continuous fibers were placed into the mold, before pouring the concrete (figure $3 \mathrm{~b}$ ). The fibers were placed between the neutral axis and the bottom of the beam, since that is the zone where tensile stresses act (figure 3c). The fibers placement was made simulating prestressed small bars; 2 layers for B-5 beams, 3 layers for B- 6 beams and 4 layers for B-7 beams, with a separation between them of $15 \mathrm{~mm}$, were used.
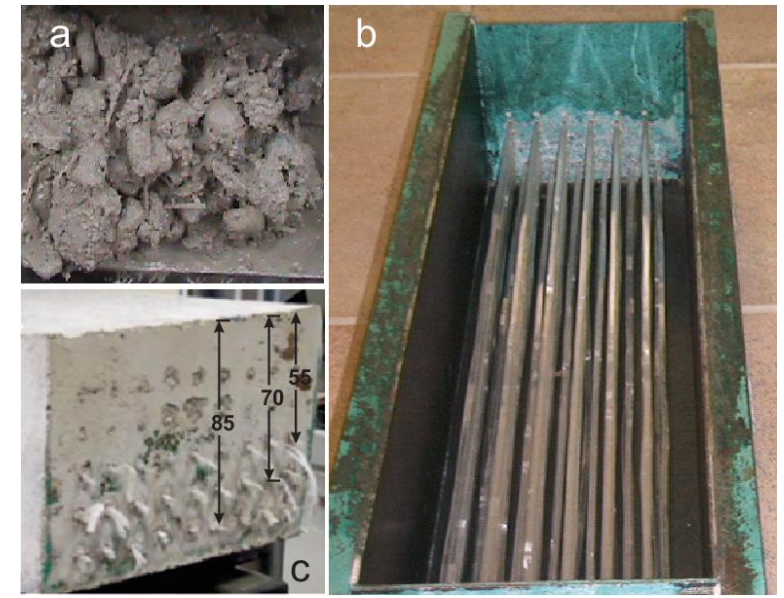

Figure 3. a) SFRC mixture showing the discontinuous short fiber dispersion in concrete mix. Fibers set up for the CFRC showing $b$ ) that continuous fibers length is equal to mold length and c) the cross section.

\section{II.4. SAMPLE CHARACTERIZATION}

\section{II.4.1 CHARACTERIZATION OF PET FIBERS}

FTIR spectroscopy analyses were done in order to determine the homogeneity and structural state of PET from different bottle brands. Spectra were recorded using a Perkin Elmer Spectrum One spectrometer with an 
attenuated total reflection (ATR) system equipped with a ZnSe prism. Each spectrum was obtained with a resolution of $1 \mathrm{~cm}-1$. On the other hand, DSC analyses were performed to determine similarities in the thermal behavior of the PET samples, using a TA Instruments Modulated DSC 2920 with an hermetic aluminum set on an air flow rate of $50 \mathrm{~cm} 3 \mathrm{~min}-1$ and a heating rate of $10^{\circ} \mathrm{C}$ min- 1 . Samples were cut into transverse sections and a mass of $4.00 \pm 0.20 \mathrm{mg}$ was used. Tension tests on the PET fibers were done by pulling the samples along the longitudinal direction (figure 4); an Instron 4469 universal testing machine with a load cell of $50 \mathrm{kN}$ was used. The displacement rate was $0.333 \mathrm{~mm} / \mathrm{s}$, with a length and width of specimen of $200 \times 3.4 \mathrm{~mm}$, respectively; the thicknesses varied in relation to the brand of the beverage bottle.

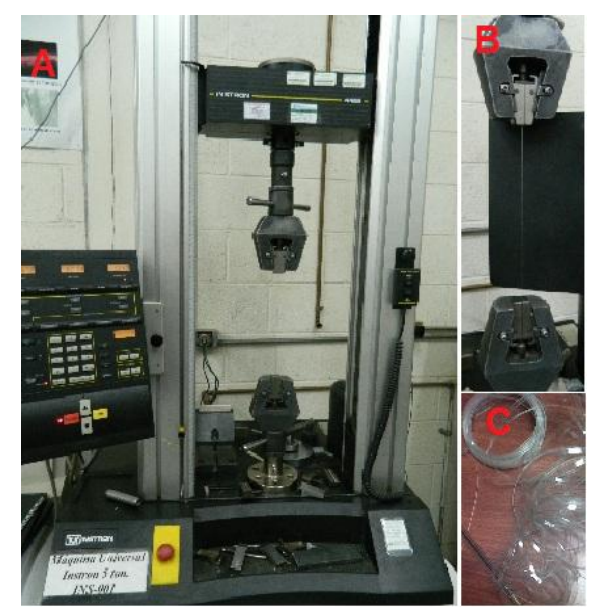

Figure 4. a) Set up used for the tensile tests, b) sample fixing in the clamps, c) recycled PET fiber specimen.

\section{II.4.2 CONCRETE COMPRESSION TESTS}

Concrete cylindrical specimens of 150 x $300 \mathrm{~mm}$ (diameter x height) were prepared in 3 groups: concrete without reinforcement (C-1), short fiber reinforced concrete with 0.25 vol.\%, 0.50 vol.\% and 1.00 vol.\% (C-2, C-3 and C-4, respectively), and continuous fiber reinforced concrete with the same percentages (C-5, C-6 and C7 , respectively) as it is indicated in table 2. Compression tests were performed using an Instron 600DX testing machine with a load cell of $600 \mathrm{kN}$ and a constant displacement rate of $0.033 \mathrm{~mm} / \mathrm{s}$, according to the ASTM C 39-01: Standard test method for compressive strength of cylindrical concrete specimens. A compressometerextensometer was adapted to the test machine to determine the Young's modulus of samples in accordance with ASTM C 469-94: Standard test method for static modulus of elasticity and Poisson's ratio of concrete in compression. To avoid great dispersion in the mechanical properties, when the compressive tests were performed, the age of the concrete specimens could have varied, searching to result in a resistance of $20 \pm 2$ $\mathrm{MPa}$ in each of them.

Table 2. Mixtures used to manufacture the specimens of FRC.

\begin{tabular}{cccc}
\hline \multicolumn{2}{c}{ Specimen } & \multicolumn{3}{c}{ Reinforcing fiber (vol.\%) } \\
Cylindrical & Beam & Short & Continuous \\
\hline C-1 & B-1 & - & - \\
C-2 & B-2 & 0.25 & - \\
C-3 & B-3 & 0.50 & - \\
C-4 & B-4 & 1.00 & - \\
C-5 & B-5 & - & 0.25 \\
C-6 & B-6 & - & 0.50 \\
C-7 & B-7 & - & 1.00 \\
\hline
\end{tabular}

\section{II.4.3 CONCRETES FLEXURAL TESTS}

For the flexural tests, beams with the detailed dimensions in figure 5 were prepared. The flexural specimens were classified as following: OC (B-1), SFRC (B2, B3 and B4) and CFRC (B5, B6 and B7), as can be seen in table 2. Three-point bending tests were performed in an Instron 600DX testing machine with a load cell of $600 \mathrm{kN}$ and a constant displacement rate of $0.025 \mathrm{~mm} / \mathrm{s}$. The deflection in beams was measured using a LVDT deflection sensor with a range of $\pm 100 \mathrm{~mm}$. The tests were conducted according to the ASTM C293-10: Standard Test Method for Flexural Strength of Concrete (Using Simple Beam with Center-Point Loading). A repeatability of three tests for each percentage was considered. 

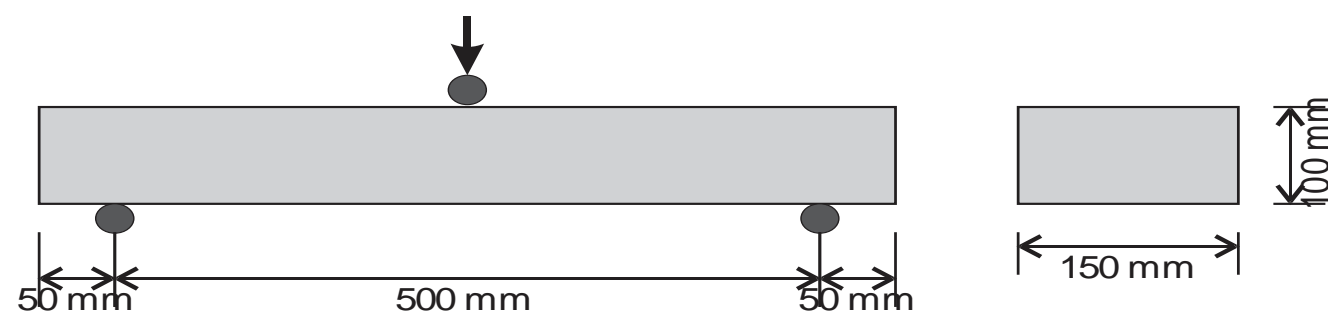

Figure 5. Dimensions of the concrete beams used for the bending tests.

\section{RESULTS AND DISCUSSION}

\section{III.1 FTIR SPECTROSCOPY OF PET}

Figure 6 shows the FTIR spectra of the 6 different PET samples used. All the samples basically showed the same spectrum: the C-H bond appears at $2968 \mathrm{~cm}-1$; an intense peak that corresponds to the stretching vibration of $\mathrm{C}=\mathrm{O}$ bond is present at $1716 \mathrm{~cm}-1$; the stretching vibrations of benzene ring $\mathrm{C}-\mathrm{C}$ bonds occur in pairs at $1500 \mathrm{~cm}-1$ and $1410 \mathrm{~cm}-1$; the bending of benzene ring $\mathrm{C}-\mathrm{H}$ bond is shown at $1340 \mathrm{~cm}-1$; the stretching vibration of the asymmetric $\mathrm{C}-\mathrm{O}$ bond appears at $1246 \mathrm{~cm}-1$ and $1018 \mathrm{~cm}-1$; meanwhile, for the same bond the symmetric vibrations occur at $1118 \mathrm{~cm}-1$ and $1098 \mathrm{~cm}-1$ for the crystalline and amorphous phases, respectively; the out-of-plane bending vibration associated to the aromatic rings is observed at $873 \mathrm{~cm}-1$; another intense peak appears at $723 \mathrm{~cm}-1$ due to the bending vibration of $\mathrm{C}-\mathrm{H}$ bond.

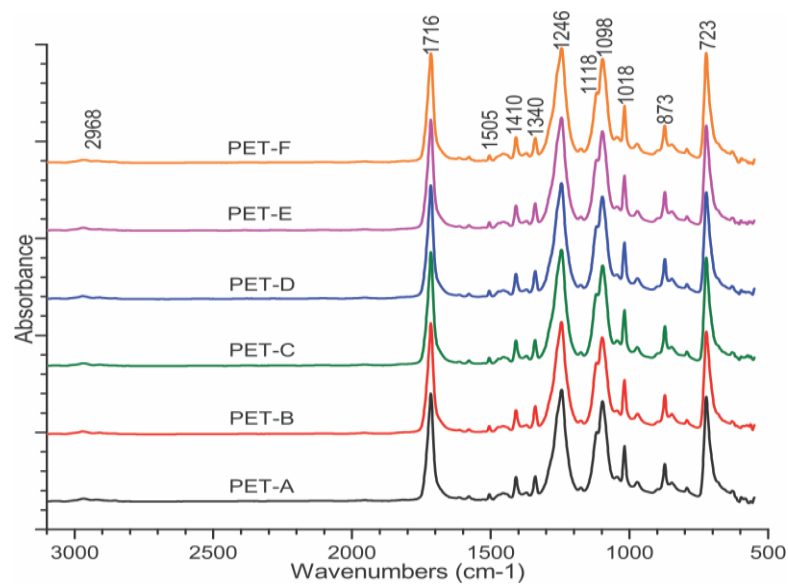

Figure 6. FTIR spectra of the PET A, B, C, D, E and F.

\section{III.2 DSC THERMOGRAMS OF PET}

The DSC thermograms of all the PET samples tested are reported in figure 7. Slight differences were observed with the following results: a crystallization peak was observed when increasing the temperature at $109 \pm 12^{\circ} \mathrm{C}$. A wide, structured, endothermic peak, associated with fusion of PET, was observed at $248 \pm 4^{\circ} \mathrm{C}$. Integration under the peaks associated with melting allowed the enthalpy of fusion to be calculated in comparison to the value of a perfect crystal of PET. The calculated degree of crystallinity was $23 \pm 1 \%$.

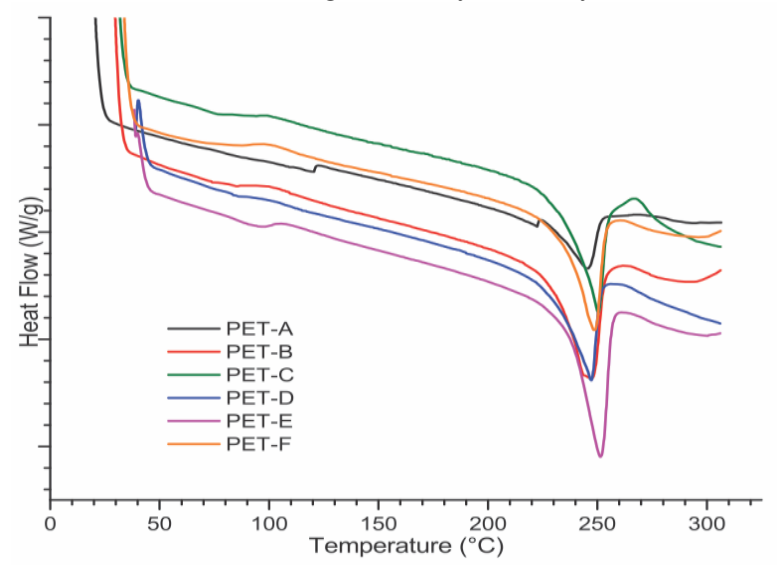

Figure 7. DSC thermograms of PET samples. 


\section{III.3 MECHANICAL CHARACTERIZATION OF PET}

The tensile stress-strain curves for each PET sample can be seen in figure 8. The general shape of the curves is consistent with previously observed deformation behavior of PET [2]. The Young's modulus measured from the initial linear regime of the stress-strain curves was $3830 \pm 47 \mathrm{MPa}$ and had a minor variation from one sample to another. However, a clear distribution of tensile strength of the elastic behavior is visible, which was $108 \pm 15 \mathrm{MPa}$.

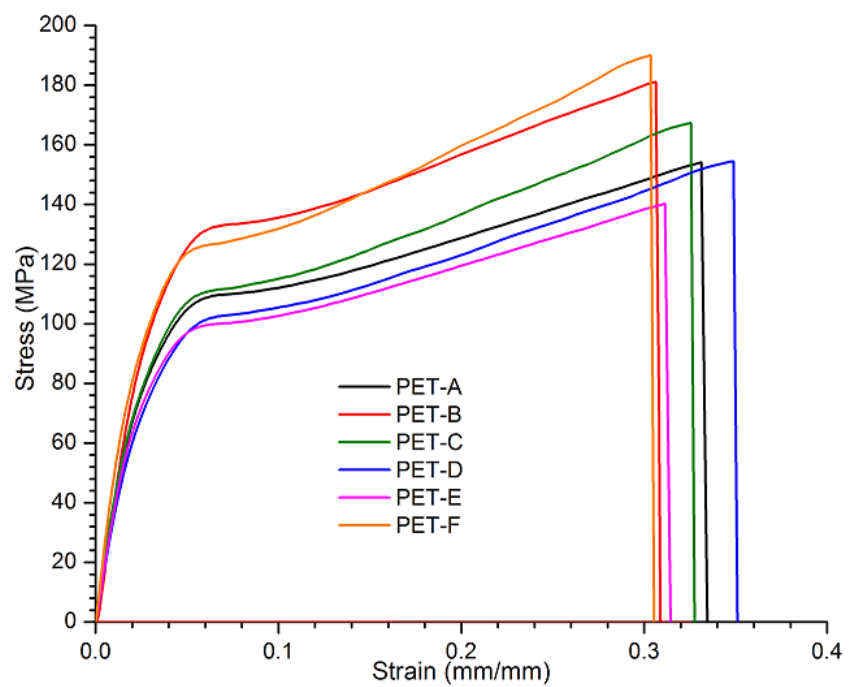

Figure 8. Stress-deformation plot of the recycled PET fibers.

\section{III.4 MECHANICAL CHARACTERIZATION OF CONCRETES}

The average values of the compressive strength ( $\left.f^{\prime} c\right)$ for the OC samples are given in Table 3 . It can be seen that all the samples had almost the same strength $(21.08 \pm 0.77 \mathrm{MPa})$ and modulus of elasticity $(1888 \pm$ $151 \mathrm{MPa}$ ). The f'c was determined in cylindrical specimens for each beam tested, which was obtained from the same mixture. Table 4 presents the flexural ultimate load (Pmax), the maximum deflection ( $\delta$ max) and the modulus of rupture (R) for the OC and FRC samples. As it can be seen, the fiber incorporation into the concrete mixture notably increased the flexural strength and the deformation capacity, compared to those of the control beam (B-1). Indeed, there was an increase of $12 \%$ and $45 \%$ in flexural strength and deformation by adding 0.25 vol.\% of short fibers (B2), respectively; the increase was $14 \%$ and $272 \%$ for 0.50 vol. $\%$ of short fibers (B3), respectively. In the case of beams reinforced with 1.00 vol.\% of short fibers (B4), even when the increment in flexural strength (9\%) was lower than the case of B3 samples, the increment in deformation capacity was $887 \%$. When the concrete beams were reinforced with continuous fibers, the results were much better: with $0.25 \mathrm{vol} . \%$ of continuous fibers (B5) the increase in flexural strength and deformation was 66\% and 585\%, respectively; for $0.50 \mathrm{vol} . \%$ of continuous fibers (B6) this values were $87 \%$ and $1440 \%$, respectively. Finally, the values for 1.00 vol. \% of continuous fibers (B7) were $179 \%$ and $1945 \%$, respectively. In the concern of the rupture modulus, for samples reinforced with short fibers (B-2, B-3 and B-4) the value slightly increased in relation to that of the B-1 samples $(2.49 \mathrm{MPa})$ and remained relatively constant $(\sim 2.8 \mathrm{MPa})$. However, the increase in the rupture modulus was higher (4.12, 4.65 and 6.94, respectively) in samples reinforced with continuous fibers (B-5, B-6 and B-7). These results highlight the importance of strengthening the concrete only in zones working in tension.

The load-deflection curves obtained experimentally from the concrete beam tests are shown in figure 9 . The results showed a very consistent elastic behavior for all specimens before cracking, evidencing their likeness regardless of the fiber content and length; nevertheless, the behavior showed some differences for the plastic zone. When the fiber content was $0 \%(\mathrm{~B}-1)$, the samples collapsed next to the elastic zone causing a sudden decrease in load; for samples containing short fibers as reinforcement (B-2 to B-4), the load fell down in a less abrupt way but without a substantial improvement in the load recovery. As for CFRC beams (B-5 to B-7), an evident improvement in the flexural behavior was observed, these beams experimented a momentary loss in load capacity and a sudden increase in deflection. This event is due to the fact that the PET fibers, which were acting just in the zone under tensile stresses, remained bonded to the concrete matrix. In this way, the beams were able to continue absorbing the load with a high deflection; the definitive failure was reached after some fiber rupture. This phenomenon is attributed to the fact that, despite the cracks formation at the deflection point at maximum load supported by OC, the tensile load was supported by the PET fibers, which is why the load increased and decreased repeatedly. 
Table 3. Compression tests results of the OC and FRC samples.

\begin{tabular}{cc}
\hline Specimen & f'c \\
Cylindrical & $\mathrm{MPa}$ \\
\hline C-1 & 21.71 \\
C-2 & 20.90 \\
C-3 & 21.43 \\
C-4 & 20.72 \\
C-5 & 21.85 \\
C-6 & 20.58 \\
C-7 & 20.31 \\
\hline
\end{tabular}

Table 4. Bending tests results of the OC and FRC samples.

\begin{tabular}{cccc}
\hline $\begin{array}{c}\text { Specimen } \\
\text { Beam }\end{array}$ & $\begin{array}{c}\text { Pmax } \\
\text { KN }(\%) \mathrm{a}\end{array}$ & $\begin{array}{c}\delta \max \\
\mathrm{mm}(\%)^{\mathrm{a}}\end{array}$ & $\begin{array}{c}\mathrm{R} \\
\mathrm{MPa}\end{array}$ \\
\hline B-1 & 4.97 & 1.68 & 2.49 \\
B-2 & $5.59(12)$ & $2.43(45)$ & 2.80 \\
B-3 & $5.66(14)$ & $6.25(272)$ & 2.83 \\
B-4 & $5.43(9)$ & $16.58(887)$ & 2.72 \\
B-5 & $8.24(66)$ & $11.51(585)$ & 4.12 \\
B-6 & $9.29(87)$ & $25.87(1440)$ & 4.65 \\
B-7 & $13.87(179)$ & $34.35(1945)$ & 6.94
\end{tabular}

${ }^{a}$ Values in parentheses correspond to the percent increase in properties in relation to those of the ordinary concrete (B-1).

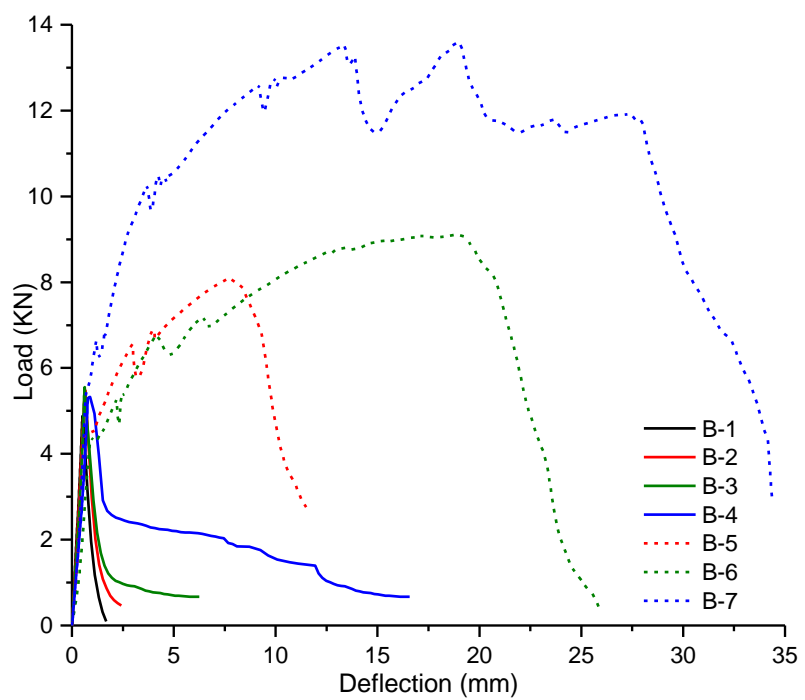

Figure 9. Load-deflection plots of the OC and FRC.

When bending tests are conducted, an important parameter to be considered is the energy absorption at the failure point. The histogram of figure 10 exhibits the amount of the absorbed energy for each beam group tested in bending. In all the cases, the absorbed energy was increased with the addition of PET fibers to the concrete, being higher as the fiber content increased. For specimens reinforced with short fibers (B-2 to B-4), even though the maximum loads (figure 9) are quite similar to those of the ordinary concrete (B-1), the area under the load-displacement curve is wider for the previous specimens. B-2 and B-3 specimens had absorbed energy values similar to that of the B-1 samples, whereas B-4 specimens had a value about 10 times greater compared with B-1. A clear enhancement of the energy absorption ability was observed for samples reinforced with continuous fibers (B-5 to B-7), surpassing from 12 to 86 times, respectively in the value of the B-1 samples. 
A great difference in absorbed energy values was observed when compared the samples reinforced with short fiber with those reinforced with continuous fibers, but with the same fiber content (B-2 vs B-5, B-3 vs B-6 and B-4 vs B-7). This highlights once again the importance of reinforcing the concrete in zones under tension.

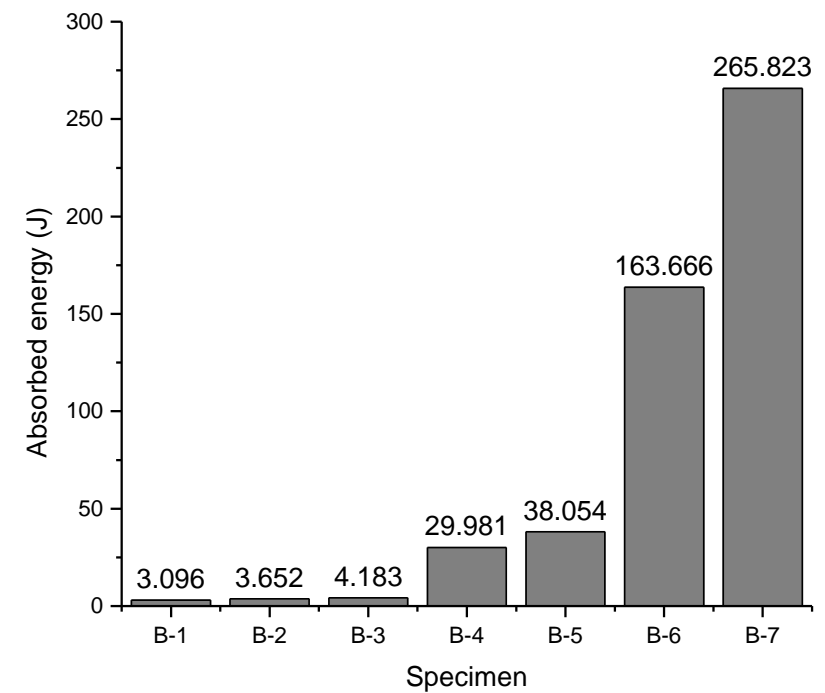

Figure 10. Absorbed energy for each group of concrete beams.

The cracking pattern for the samples tested in bending were compared (figure 11) in order to determine the fracture behavior of the concretes in study. All the control beams (OC) had the same cracking behavior (figure 11A), showing at the beam midpoint a single crack at $90^{\circ}$ in relation to the beam horizontal axis and resulting in a sudden collapse with a conventional failure. The SFRC beams (figure 11B) showed a cracking pattern similar to that of the OC beams, with the difference that the crack aperture was wider and the collapse was not very abrupt. This fact was attributed to the sewing effect generated by the fibers on the concrete matrix. Concerning the CFRC beams (figure 11C), the cracking pattern observed was significantly different from those showed in the OC and SFRC samples: a first crack at $90^{\circ}$ appeared (crack 1, figure 11C) but not fully developed along the beam thickness; a second crack at $\sim 70^{\circ}$ emerged (crack 2, figure 11C), which neither was fully developed because a crack branching adhered to cracks 1 and 2 (indicated by arrows in figure 11C) developed. Afterwards cracks 1 and 2 propagated, leading to the beams to fail. During the observation it was noticed that the fibers impeded the beam separation, pointing out that these did not pull out, because of their good adhesion with the concrete matrix. Besides, it was observed that as the content of continuous fibers was increased the appearance of multi-cracks was higher, which gave the samples the ability to increase their flexural properties.

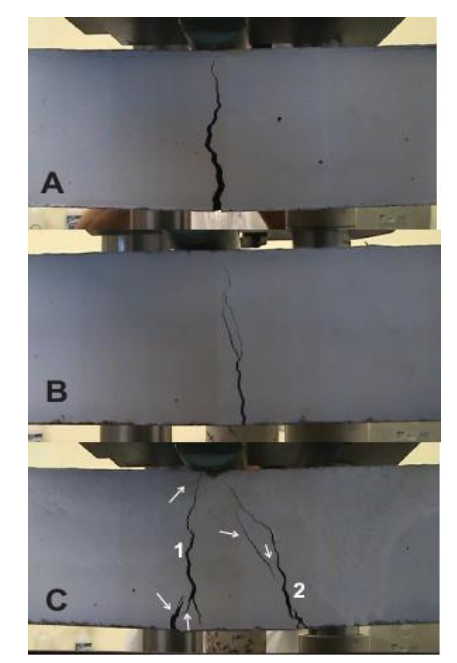

Figure 11. Concrete beams in the course of the bending tests, showing the cracking patter: a) OC, b) SFRC and c) CFRC samples.

\section{CONCLUSION}

In this paper, the behavior of concretes reinforced with both short-dispersed and continuous PET fibers has been investigated using bending tests. A method to obtain continuous recycled PET fibers was developed. 
Also, a new way of mounting such fibers into the mold has been developed, fibers were set prestressed between the neutral axis and the bottom of the beams, where tensile stresses act when beams are under bending stresses. A series of tests on PET fiber reinforced concretes has been performed. The results were compared with those of the ordinary concrete, obtaining the following main conclusions:

1. A high adherence between PET fibers and concrete matrix was achieved.

2. An increment in the flexural strength, ductile behavior and energy absorption capacity was obtained, mainly with the continuous fiber reinforced concretes.

3. Waste PET bottle fibers could be considered for the reinforcement of concrete; further studies could elucidate if these fibers may be used as structural material for construction.

Furthermore, the fact of using waste PET bottles as reinforcing material contributes to generate a benefit to the environmental preservation.

A conclusion section must be included and should indicate clearly the advantages, limitations, and possible applications of the paper. Although a conclusion may review the main points of the paper, do not replicate the abstract as the conclusion. A conclusion might elaborate on the importance of the work or suggest applications and extensions.

\section{ACKNOWLEDGEMENTS}

FJBL was supported as a graduate student by CONACYT (grant 241960). This research was supported by CONACYT-Red Temática de Nanociencias y Nanotecnología and project PROFAPI 2013/41. The authors thank the technical assistance of L. de la Torre-Saenz, D. Lardizabal-Gutierrez and J.A. Hernandez-Gutierrez.

\section{REFERENCES}

[1] Kim SB, Yi NH, Kim HY, Kim J-HJ, Song Y-C. Material and structural performance evaluation of recycled PET fiber reinforced concrete. Cement Concrete Comp, 32, 2010:232-240.

[2] Dora F. Preliminary analysis of concrete reinforced with waste bottles PET fibers. Constr Build Mater, 25, 2011:1906-1915.

[3] Batayneh M, Marie I, Asi I. Use of selected waste materials in concrete mixes. Waste Manage, 27, 2007:1870-1876.

[4] Juárez C, Guevara B, Valdez P, Durán-Herrera A. Mechanical properties of natural fibers reinforced sustainable masonry. Constr Build Mater, 24, 2010:1536-1541.

[5] Siddique R, Khatib J, Kaur I. Use of recycled plastic in concrete: A review. Waste Manage, 28, 2008:1835-1852.

[6] Choi YW, Moon DJ, Kim YJ, Lachemi M. Characteristics of mortar and concrete containing fine aggregate manufactured from recycled waste polyethylene terephthalate bottles. Constr Buil Mater, 23, 2009:2829-2835.

[7] Mahdi F, Abbas H, Khan AA. Strength characteristics of polymer mortar and concrete using different compositions of resins derived from post-consumer PET bottles. Constr Build Mater, 24, 2010:25-36.

[8] Won J-P, Jang C-I, Lee S-W, Lee S-J, Kim H-Y. Long-term performance of recycled PET fibrereinforced cement composites. Constr Build Mater, 24, 2010:660-665.

[9] Kashyap J, Willis CR, Griffith MC, Ingham JM, Masia MJ. Debonding resistance of FRP-to-clay brick masonry joints. Eng Struct, 41, 2012:186-198.

[10] Wang Z, Wang D, Smith ST, Lu D. Experimental testing and analytical modeling of CFRP-confined large circular RC columns subjected to cyclic axial compression. Eng Struct, 40, 2012:64-74.

[11] Yao C, Nakashima M. Application of headed studs in steel fiber reinforced cementitious composite slab of steel beam-column connection. Earthq Eng Eng Vib, 11, 2012:11-21.

[12] Mostofinejad D, Mohammadi Anaei M. Effect of confining of boundary elements of slender RC shear wall by FRP composites and stirrups. Eng Struct, 41, 2012:1-13.

[13] Yesilata B, Isiker Y, Turgut P. Thermal insulation enhancement in concretes by adding waste PET and rubber pieces. Constr Build Mater, 23, 2009:1878-1882.

[14] Ochi T, Okubo S, Fukui K. Development of recycled PET fiber and its application as concretereinforcing fiber. Cement Concrete Comp, 29, 2007:448-455.

[15] Fraternali F, Ciancia V, Chechile R, Rizzano G, Feo L, Incarnato L. Experimental study of the thermomechanical properties of recycled PET fiber-reinforced concrete. Compos Struct, 93, 2011:2368-2374.

[16] Pereira de Oliveira LA, Castro-Gomes JP. Physical and mechanical behaviour of recycled PET fibre reinforced mortar. Constr Build Mater, 25, 2011:1712-1717. 